\title{
EFFECT OF HEALTH EDUCATION AND "PREGNANT MOTHER AWARENESS MOVEMENT" ON KNOWLEDGE AND COMMUNITY PARTICIPATION IN SAFE MOTHERHOOD, IN TANGERANG, BANTEN
}

\author{
Novendy ${ }^{1)}$, Adrian Pratama1), Fany Azhar ${ }^{1)}$, Marsha Marcelina' ${ }^{1}$, \\ Meli Ardianti' ${ }^{1}$, Muhammad Faridzi Fikri²) \\ 1) Department of Public Health, Faculty of Medicine, \\ Tarumanegara University, Jakarta \\ 2) Community Health Center (Puskesmas), Tangerang, Banten
}

\begin{abstract}
BACKGROUND: Neonatal mortality, infant mortality, and maternal mortality remained important public health in most developing countries, including Indonesia. Neonatal mortality rate in Puskesmas Kronjo, Tangerang Banten was 6 per 1000 live birth in 2014, and 7 per 1000 live birth in 2015. There is a need to assess the effect of health education and community awareness program on the knowledge in safe motherhood and number of antenatal care visits. This study aimed to determine effect of health education and "pregnant mother awareness movement" on knowledge and community participation in safe motherhood.

SUBJECT AND METHODS: This was a quasi-experimental study, before and after intervention with no control design, conducted in Tangerang, Banten. A sample of 25 pregnant mothers was selected from Community Health Center (Puskesmas) Kronjo, Tangerang, Banten. The dependent variables were knowledge in safe motherhood and community participation in maternal care. The independent variable was a program consisting of health education and "Pregnant Women Awareness Movement" (Gerakan Peduli Ibu Hamil (GeLiBuMil). The health education was intended to give information on the important antenatal care and other safe motherhood services. The "Pregnant Women Awareness Movement" aimed to increase awareness of safe motherhood. A questionnaire was used to measure knowledge before and after the intervention. Document review was used to collect on community participation in safe motherhood. Change in percentage of pregnant mothers who had good knowledge in safe motherhood before and after intervention was estimated by Odds Ratio and tested by Chi Square test.

RESULTS: Health education and "Pregnant Women Awareness Movement" altogether increased knowledge in safe motherhood among pregnant mothers. Pregnant mothers who received this intervention program were 3.19 times more likely to have good knowledge in safe motherhood than those who did not receive the program $(\mathrm{OR}=3.19 ; 95 \% \mathrm{CI}=1.00$ to $10.17 ; \mathrm{p}=0.047)$. There was $12 \%$ increase in the number of visit among pregnant mothers to use antenatal and other maternal care.
\end{abstract}


CONCLUSION: Health education and "Pregnant Women Awareness Movement" can effectively increase knowledge in safe motherhood and antenatal visits among pregnant mothers.

Keywords: neonatal mortality rate, antenatal care, health education, community awareness 